\title{
Soft-sediment benthic biodiversity on the continental shelf in relation to environmental variability
}

\author{
Kari Elsa Ellingsen* \\ Section of Marine Zoology and Marine Chemistry, Department of Biology, University of Oslo, PO Box 1064 Blindern, \\ 0316 Oslo, Norway
}

\begin{abstract}
Soft-sediment macrobenthos data for the Norwegian continental shelf $\left(61^{\circ} \mathrm{N}, 1\right.$ to $\left.2^{\circ} \mathrm{E}\right)$ was used to examine species distributions, community structure and community differences, and how different measures of biodiversity are related to environmental variability. Water depth at 35 sites ranged from 115 to $331 \mathrm{~m}$ over a spatial sampling scale of ca. $45 \mathrm{~km} \times 60 \mathrm{~km}$, and there was considerable variation in sediment characteristics. Of a total of 508 recorded species, $39 \%$ were restricted to 1 or 2 sites, whereas only 3 species spanned the entire sampling area. Polychaetes were the most common and widespread taxonomic group; crustaceans and echinoderms were more restricted in their distributions than the other dominant groups. Whittaker's beta diversity measure ( $\beta_{\mathrm{W}}$, extent of change in species composition among sites) was highest for those groups with the highest proportion of restricted-range species. The number of shared species, the complementarity (biotic distinctness), and the Bray-Curtis similarity between all pairwise combinations of sites ( 3 beta diversity measures) were more strongly related to change in environment (notably depth, followed by median grain size and silt-clay content) than to spatial distance between sites. Likewise, a multivariate analysis (BIOENV) identified these factors as the major environmental variables influencing the faunal patterns, whereas univariate measures of diversity were not related to depth or median grain size. Univariate measures of diversity, beta diversity measures, and BIO-ENV analyses showed that molluscs, followed by polychaetes, were most highly related to environmental variables. In this study, alpha, beta and gamma diversity were higher than in a study of a single soft-sediment habitat type in the southern part of the Norwegian continental shelf.
\end{abstract}

KEY WORDS: Soft-sediment communities - Marine biodiversity · Alpha diversity · Beta diversity • Gamma diversity · Distributions · Environmental variability

Resale or republication not permitted without written consent of the publisher

\section{INTRODUCTION}

In recent years, biological diversity has received increased interest. Most studies relate to terrestrial systems, and knowledge of marine biodiversity lags far behind that of land systems. Oceans cover about $70 \%$ of the earth, and sedimentary habitats cover most of the ocean bottom (Snelgrove et al. 1997). The macrobenthos in marine sediments play important roles in

*E-mail: k.e.ellingsen@bio.uio.no ecosystem processes such as nutrient cycling, pollutant metabolism, dispersion and burial, and in secondary production (Snelgrove 1998). It is therefore important to improve our understanding of biodiversity in marine sediments. Marine systems differ from terrestrial systems in a number of ways, and paradigms concerning terrestrial patterns of biodiversity may not be applicable to marine situations (May 1994, Gray 1997, Heip et al. 1998). Many benthic species have pelagic larvae that remain floating in the water for days or months, and since unlike most terrestrial systems, barriers to dispersal are relatively weak, many species may dis- 
perse over much broader ranges than on land. Subtidally, where sediments tend to grade into each other, the boundaries are less distinct than on land and the extent of a habitat or assemblage often cannot be determined (Gray 2000). Coastal marine benthic communities are threatened by human activities, and the present rate of habitat degradation is alarming (Gray 1997, Snelgrove et al. 1997). Given that only a small fraction of the benthic organisms that reside on or are buried in sediments have been described, it is likely that species are being lost without ecologists knowing they existed (Snelgrove 1998, 1999).

The number of species has been the traditional measure of biodiversity in ecology and conservation, but the abstract concept of biodiversity as the 'variety of life' (Gaston 1996) cannot be encompassed by a single measure (Harper \& Hawksworth 1994, Heywood \& Watson 1995, Warwick \& Clarke 1995). Local richness and biotic differences are positive components of biodiversity, whereas biotic similarity is negatively related to overall biodiversity (Colwell \& Coddington 1994). Ellingsen (2001) evaluated different measures of marine biodiversity, and suggested that, in addition to species diversity, distributions of species and community differences should be taken into account when measuring marine biodiversity and planning conservation areas.

There is no single correct scale at which ecosystems can be described; patterns and variability are likely to change with scale (Levin 1992, Thrush et al. 1997, Ward et al. 1998). Existing biodiversity studies are uneven in terms of spatial scales, sampling methods and effort, as well as statistical analysis, thus making comparisons difficult between data from different studies. Whittaker (1960) pioneered the partitioning of species diversity into alpha $(\alpha)$, beta $(\beta)$ and gamma $(\gamma)$ components. Following Whittaker, a sample or site is typically, as in this study, used to describe $\alpha$ diversity (local scale), whereas $\gamma$ diversity is computed by merging a number of samples over a larger and frequently entirely arbitrary spatial scale. Most marine surveys have been carried out on small scales, and although data from large areas exist (e.g. from monitoring surveys of the oil and gas industry in the North Sea), they have as yet seldom been used in a context of measuring biodiversity at larger scales. Beta diversity is based on ratios or differences and is not related to spatial scales (Whittaker 1972). Although there have been a number of studies of $\alpha$ diversity in marine systems, investigations of $\beta$ diversity have been few (Gray 2000). Among taxa, $\beta$ diversity may be expected to be highest in those with the most restricted ranges and specialised habitats, whereas within taxa, $\beta$ diversity may increase with the environmental dissimilarity between sites (Harrison et al.
1992). Interactions between $\beta$ diversity-distance and $\beta$ diversity-habitat change are also ecologically interesting (Harrison et al. 1992), but as yet few studies have been undertaken with marine data (but see Price et al. 1999 and Clarke \& Lidgard 2000). In marine softbottom studies, multivariate methods have proven much more sensitive to small changes in faunal composition than univariate methods (Gray et al. 1990, Warwick \& Clarke 1991, 1993). A multivariate measure of $\beta$ diversity would therefore be expected to provide more information than univariate measures.

Over the last few decades, the relationship between the distribution and diversity of soft-sediment species and the sediments in which they reside have been the subject of numerous studies (see e.g. Sanders 1968, Gray 1974, Rhoads 1974, Whitlatch 1981, Etter \& Grassle 1992, Snelgrove \& Butman 1994). Sediment grain size, organic content, microbial content, food abundance as well as water depth are among the factors that have been related to community structure. One question that arises is how different measures of biodiversity are related to environmental variables within a given latitudinal area. Multivariate measures of biodiversity would be expected to have closer relationships to environmental variables than univariate measures. Heterogeneous sediments, with more potential niches, seem to have a higher diversity than homogeneous sediments (e.g. Gray 1974). Thus, different measures of biodiversity would be expected to vary with different levels of environmental variability. The present paper concerns the spatial patterns of the fauna in relation to environmental variability.

The present study used soft-sediment macrobenthos data from the Norwegian continental shelf $\left(61^{\circ} \mathrm{N}, 1\right.$ to $2^{\circ} \mathrm{E}$ ). The area was chosen in order to study distributions of species, and community structure and differences over a rather large area $(45 \times 60 \mathrm{~km})$ covering a range of depths (115 to $331 \mathrm{~m}$ ) and sediment characteristics (median grain size, $M d \varphi$ : 0.35 to 6.09 ) (i.e. the area probably consists of several soft-sediment habitats). The distribution of the species range size for the 4 dominant taxonomic groups of the soft-sediment communities (polychaetes, molluscs, crustaceans, and echinoderms) was investigated, and a comparison made of Whittaker's $(1960,1972)$ beta diversity measure $\left(\beta_{W}\right)$ between these groups. The number of shared species, complementarity (biotic distinctness) (Colwell \& Coddington 1994) and the Bray-Curtis similarity (Bray \& Curtis 1957) between all pairwise combinations of sites are related to spatial distance and changes in environmental variables and used as further measures of $\beta$ diversity. The data are analysed with methods similar to those used in Ellingsen's (2001) study in a single soft-sediment habitat type on the southern part of the Norwegian continental shelf $\left(56\right.$ to $\left.57^{\circ} \mathrm{N}\right)$ in order to 
compare these 2 data sets. The main objective of this study was to examine the relationships between different measures of biodiversity and environmental variability over relatively large spatial scales.

\section{MATERIALS AND METHODS}

The data were collected in May-June 1996 on the Norwegian continental shelf as part of a routine environmental monitoring survey of the effects of oil and gas industry on the seabed. The Norwegian Pollution Control Authority (SFT) has divided the Norwegian continental shelf into 'regions', based on the localisation of installations, of which this data set is from Region IV. Whilst most continental shelves have a depth limit of about $200 \mathrm{~m}$, this is not so for the Norwegian shelf, where there are deeper areas in the Norwegian Trench (which runs parallel to the Norwegian coast) and in the Skagerrak. Total sampling coverage spanned ca $60 \mathrm{~km}$ in a south-north direction and ca $45 \mathrm{~km}$ from east to west $\left(61^{\circ} 01^{\prime}\right.$ to $61^{\circ} 31^{\prime} \mathrm{N}, 1^{\circ} 48^{\prime}$ to $2^{\circ} 38^{\prime} \mathrm{E}$ : Fig. 1). Water depth at 35 sites in the study area ranged from 115 to $331 \mathrm{~m}$, and there was considerable variation in median grain size $(\mathrm{Md} \varphi$ range: 0.35 to 6.09 ) and silt-clay content (0 to $62 \%$ ) among sites (see Table 1). Generally, the deeper north-eastern part of the study area (in the Norwegian Trench) had finer sediments with a higher content of total organic matter than the shallower southwestern part.

The positioning equipment comprised a differential Global Positioning System. Physical, chemical and biological samples were collected with a $0.1 \mathrm{~m}^{2}$ van Veen grab. At each site, 3 grabs were taken for analyses of sediment variables. Sub-samples were taken from the upper $5 \mathrm{~cm}$ of 1 grab for analyses of median grain size, sorting, skewness and total organic matter, and from the upper $1 \mathrm{~cm}$ of 3 grabs for analyses of metals and hydrocarbons. Five additional replicates were taken at each site for analyses of benthic macrofauna. Biological samples were washed through a $1 \mathrm{~mm}$ diam. round-hole sieve, and the retained fauna were fixed in formalin for later identification to the lowest practical taxonomic level. Additional details of sampling and analyses are given in Jensen et al. (1997).

Faunal groups not properly sampled by the methods used, such as Nematoda, Foraminifera and inhabitants of hard substrata such as Bryozoa and Porifera, were not included in the data analyses. Likewise, juveniles were excluded, and unidentified species were not included if they could be mistaken for identified species. In soft-sediment studies a single grab, covering only $0.1 \mathrm{~m}^{2}$, is known to sample only a small fraction of the species at a site because of small-scale spatial variation. Furthermore, the variability among grabs taken from a single site is known to be high. Pooling data across grabs evens out the high variability among them and gives a more representative picture of the community structure at a site. Data analyses were therefore done on species abundance data pooled over 5 replicate grabs from each site. Only data from sites uncontaminated by oil or gas activities were used. For each field these sites were identified by univariate $(S, N$, $\exp H^{\prime}, 1 / \mathrm{SI}$ ) and multivariate (CLUSTER, MDS) analyses of faunal data, as well as measured concentrations of metals and hydrocarbons (results not given here: see description of methods in the following paragraphs). The resulting 160 uncontaminated sites (Fig. 1) were not sampled with the present study in mind. For the present study, 35 sites from the whole study area were therefore selected, based on geographic localisation, in order to distribute the sites evenly through the area (i.e. the distances between adjacent sites should be as similar as possible, see Fig. 1). This data set of 35 sites was used in the following analyses if not stated otherwise.

As univariate measures of diversity species richness $(S)$, the exponentiated form of the Shannon-Wiener index $\left(\exp H^{\prime}\right)(\log$ base 2$)$ and the reciprocal of Simpson's index (1/SI) were used (see e.g. Whittaker 1972, Hill 1973, Magurran 1988). Here I follow Peet (1974) in calling $\exp H^{\prime}$ and 1/SI 'heterogeneity diversity'. Labelling of species restricted to a single site 'uniques', species occurring at exactly 2 sites only 'duplicates', species represented by a single individual 'singletons',

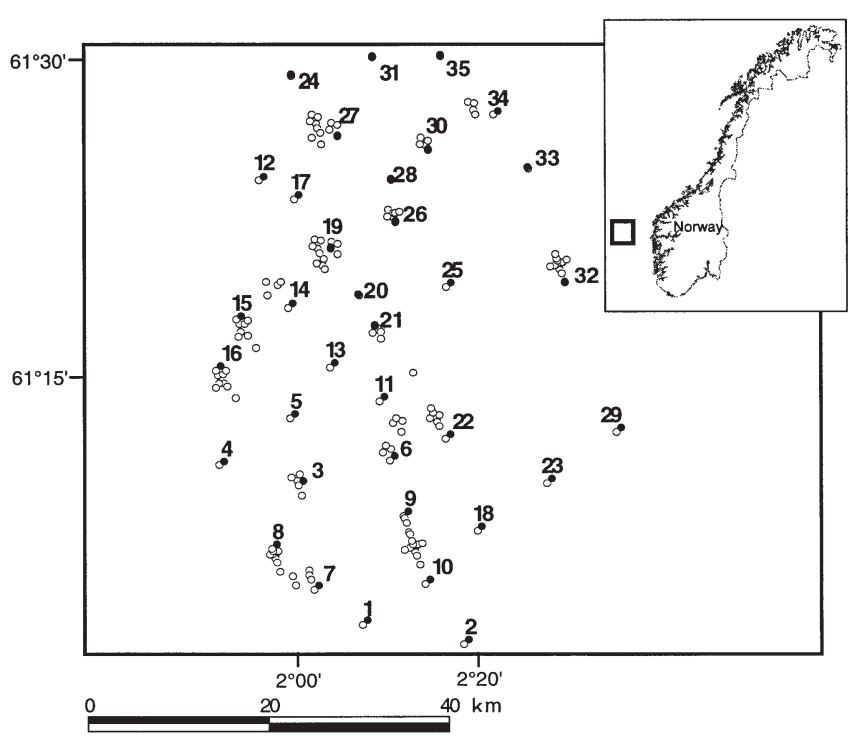

Fig. 1. Geographic positions of 160 uncontaminated sampling sites in Region IV on the Norwegian continental shelf. $(\bullet)$ Sites included in this study, i.e. 35 sites, sample numbers ordered in sequence from shallow to deep water (cf. Table 1);

( $)$ sites not included in this study 


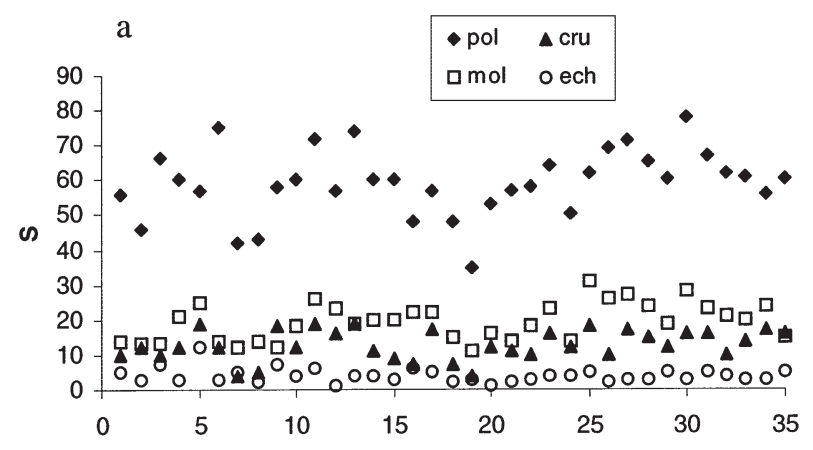

b
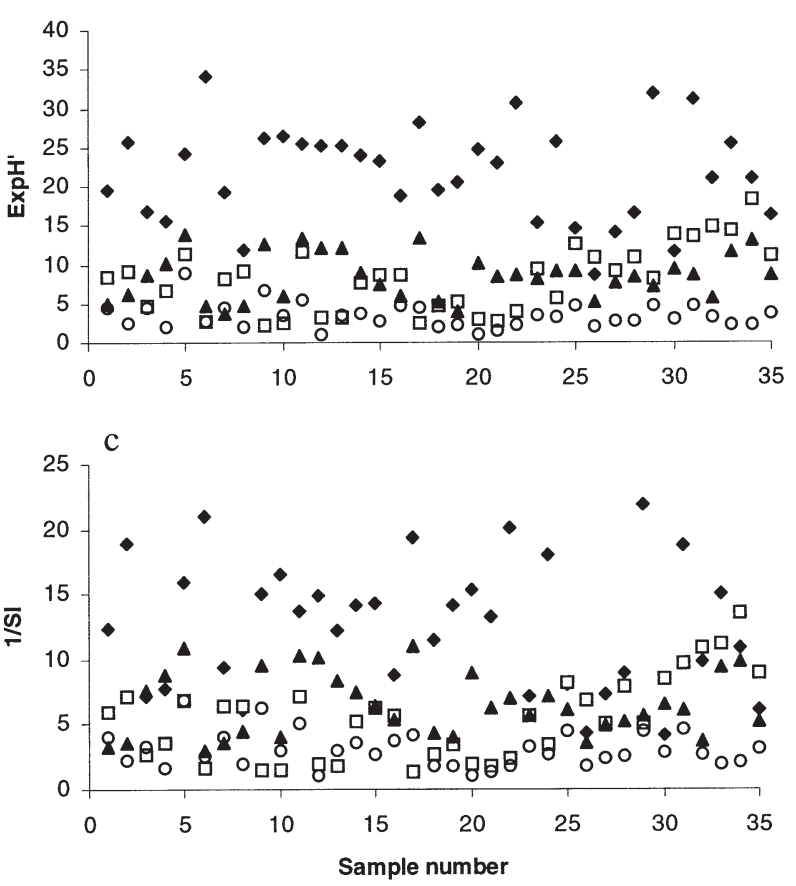

Fig. 2. Univariate measures of local community structure within dominant taxonomic groups. Samples ordered in sequence from shallow to deep water (cf. Table 1). (a) Species richness $(S)_{i}(\mathrm{~b})$ exponentiated form of the Shannon formula $\left(\operatorname{Exp} H^{\prime}\right)$ (using log base 2); (c) reciprocal of Simpsons's index $(1 / S I)$. pol: polychaetes; mol: molluscs; cru: crustaceans; ech: echinoderms

and species represented by only 2 individuals 'doubletons' follows the terminology of Colwell \& Coddington (1994). The non-parametric Chao2 method (Chao 1987, Colwell \& Coddington 1994) was used to estimate the true species richness. Here Chao2 $=S_{\text {obs }}+$ $\left(Q_{1}{ }^{2} / 2 Q_{2}\right)$, where $S_{\text {obs }}$ is the number of species observed in all samples pooled and $Q_{1}$ and $Q_{2}$ are the frequency of uniques and duplicates, respectively.

Beta diversity is the extent of change in species composition of communities among the samples of a data set or along a gradient (Whittaker 1975). Whittaker's $(1960,1972)$ original $\beta$ diversity measure, $\beta_{W}=(\gamma / \bar{\alpha})-1$, was used. Here $\gamma$ is the total number of species in the whole sampling area, $\bar{\alpha}$ is the average number of species per individual sample, and 1 sample or site is the sum of 5 grabs ( $\alpha$ diversity). This measures the proportion by which the whole area is richer than the average sites within it. Beta diversity has been measured in many different ways (discussed by Magurran 1988), but Wilson \& Shmida (1984) state that $\beta_{W}$ is perhaps the most widely used measure of $\beta$ diversity. The number of species shared for each possible pair of samples $j$ and $k\left(V_{j k}\right)$ was used as a second measure of $\beta$ diversity. As a third measure of $\beta$ diversity the biotic distinctness, or 'complementarity' $\left(C_{j k}\right)$ (Colwell \& Coddington 1994), between all pairwise combinations of sites was used. Here complementarity between 2 sites is the total number of unshared species divided by the total species richness for the 2 sites, ranging from 0 (identical samples) to $100 \%$ (completely distinct). Finally, a similarity matrix was constructed using square-root transformation and the Bray-Curtis coefficient (Bray \& Curtis 1957), and the similarity between all pairwise permutations of sites was used as a fourth measure of $\beta$ diversity.

Hierarchical, agglomerative classification (CLUSTER), employing group-average linking (e.g. Clifford \& Stephenson 1975) and ordination by nonmetric multidimensional scaling (MDS) based on the Bray-Curtis similarity matrix (e.g. Kruskal \& Wish 1978, Clarke \& Green 1988) was used. The species making the greatest contribution to the division of sites into clusters were determined using the similarity percentages procedure SIMPER (Clarke 1993). Relationships between faunal pattern (Bray-Curtis similarity matrix) and different subsets of environmental variables (matrices computed using normalised Euclidean distance) were examined using the BIO-ENV procedure (Clarke \& Ainsworth 1993). The above univariate and multivariate measurements are im-

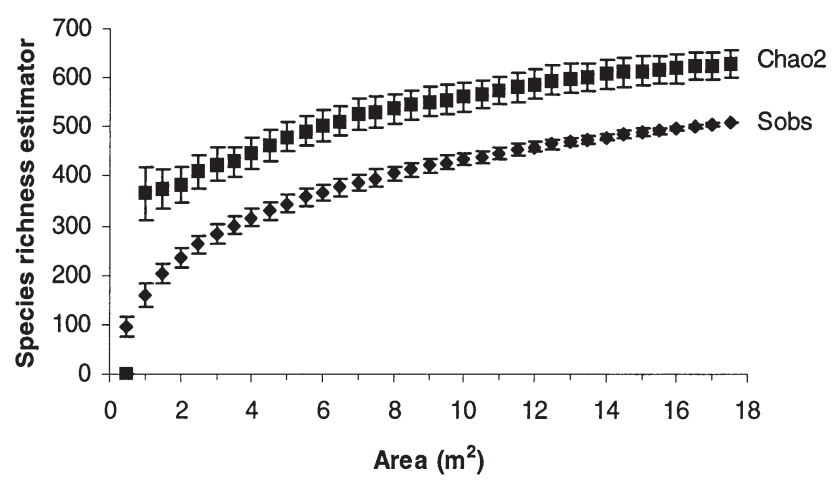

Fig. 3. Species accumulation curves. Estimators of species richness are the total number of all species $\left(S_{\text {obs }}\right)$ and the Chao2 estimator of true richness. Plotted values are means $\pm \mathrm{SD}$ of 50 estimates based on 50 randomisations of sample accumulation order (without replacement) 
plemented in the PRIMER package, described in Clarke \& Warwick (1994), and Chao2, $V_{j k}$ and $C_{j k}$ are included in the EstimateS software (Version 5, R. K. Colwell 1997, available at http://viceroy.eeb. uconn.edu/estimates). Geographic distances in kilometres were computed between all pairwise combinations of sites, using the R package (Legendre \& Vaudor 1991).

\section{RESULTS}

\section{Alpha and gamma diversity}

Sample species richness $(S)$ was highly variable (range 56 to 131), but 22 out of 35 sites contained more than 100 species (Table 1). Polychaetes displayed higher local species richness than the other dominant taxonomic groups (Fig. 2a). The heterogeneity diversity $\left(\operatorname{Exp} H^{\prime}\right.$ and 1/SI) of the dominant groups was also highly variable (Fig. 2b,c). Polychaetes displayed the highest heterogeneity diversity, with the exception of some sites with a high local abundance of the polychaetes Euchone incolor, Myriochele oculata, Amythasides macroglossus and Owenia fusiformis (Table 2). Site 30 had the highest species richness; however, as E. incolor was represented by as many as 1332 individuals $(42.4 \%)$ at this site, the heterogeneity diversity was among the lowest recorded (Table 1). A number of environmental variables were strongly positively related to each other, especially depth to median grain size and latitude, and silt-clay content to sorting and total organic matter (Table 3). Species richness for all taxa pooled was significantly correlated with a range of environmental variables, notably sediment skewness and total organic matter, but not with depth or median grain size (Table 3). Local heterogeneity diversity showed no significant relationship to measured environmental factors (Table 3). Relationships between environmental variables and univariate measures of diversity varied between the dominant taxonomic groups (Table 3). Generally, molluscs were most highly correlated with environmental factors, notably skewness, siltclay content and sorting, and only molluscs were related to depth and median grain size. Polychaetes had higher relationships with environmental variables than crustaceans and echinoderms.
Table 1. Summary of depth, sediment characteristics and univariate measures of Silt-clay: fraction of sediment $<0.063 \mathrm{~mm}(\%)$; TOM: total organic matter (\%); S: number of species; N: number of individuals; $\operatorname{Exp} H^{\prime}$ : exponentiated form of the Shannon formula; 1/SI: reciprocal of Simpson's index

\begin{tabular}{|c|c|c|c|c|c|c|c|c|}
\hline Site & Depth (m) & $\operatorname{Md} \varphi$ & Silt-clay & TOM & S & $\mathrm{N}$ & $\operatorname{Exp} H^{\prime}$ & $1 / \mathrm{SI}$ \\
\hline 1 & 115 & 1.10 & 0.0 & 1.0 & 93 & 1030 & 34.8 & 19.9 \\
\hline 2 & 115 & 1.95 & 0.0 & 0.9 & 80 & 487 & 43.3 & 30.0 \\
\hline 3 & 122 & 1.84 & 0.0 & 1.1 & 101 & 946 & 25.4 & 10.0 \\
\hline 4 & 123 & 1.70 & 6.0 & 1.3 & 103 & 1235 & 25.6 & 11.5 \\
\hline 5 & 127 & 0.35 & 0.0 & 1.5 & 120 & 829 & 47.4 & 27.0 \\
\hline 6 & 132 & 1.57 & 8.9 & 2.2 & 130 & 862 & 49.2 & 24.9 \\
\hline 7 & 135 & 1.47 & 0.0 & 0.6 & 68 & 375 & 32.7 & 15.2 \\
\hline 8 & 135 & 1.79 & 0.0 & 0.8 & 69 & 690 & 17.9 & 7.8 \\
\hline 9 & 135 & 1.04 & 0.0 & 1.5 & 105 & 723 & 38.8 & 17.9 \\
\hline 10 & 135 & 1.23 & 0.0 & 1.1 & 103 & 868 & 28.2 & 10.6 \\
\hline 11 & 136 & 1.28 & 5.7 & 3.6 & 113 & 842 & 38.5 & 16.8 \\
\hline 12 & 139 & 1.24 & 0.0 & 1.6 & 105 & 871 & 27.5 & 10.1 \\
\hline 13 & 142 & 1.11 & 7.9 & 2.0 & 124 & 1011 & 36.0 & 15.6 \\
\hline 14 & 145 & 1.73 & 18.5 & 1.2 & 99 & 856 & 37.6 & 22.1 \\
\hline 15 & 146 & 1.41 & 12.8 & 1.6 & 97 & 1188 & 36.3 & 22.1 \\
\hline 16 & 147 & 1.67 & 6.4 & 1.6 & 85 & 562 & 33.8 & 16.5 \\
\hline 17 & 160 & 1.36 & 0.0 & 2.2 & 107 & 878 & 29.5 & 10.5 \\
\hline 18 & 173 & 2.74 & 0.0 & 1.5 & 77 & 650 & 29.5 & 17.0 \\
\hline 19 & 185 & 1.85 & 0.0 & 1.6 & 56 & 256 & 30.6 & 20.5 \\
\hline 20 & 197 & 1.88 & 2.0 & 1.9 & 89 & 683 & 28.0 & 12.2 \\
\hline 21 & 198 & 2.08 & 6.5 & 2.5 & 90 & 877 & 23.1 & 9.7 \\
\hline 22 & 214 & 2.82 & 0.0 & 1.5 & 93 & 665 & 33.3 & 15.2 \\
\hline 23 & 249 & 3.89 & 28.6 & 2.2 & 112 & 1293 & 31.1 & 13.3 \\
\hline 24 & 272 & 2.90 & 0.0 & 1.1 & 81 & 531 & 39.4 & 25.4 \\
\hline 25 & 275 & 3.80 & 21.5 & 2.9 & 123 & 1450 & 30.4 & 14.2 \\
\hline 26 & 279 & 3.70 & 15.4 & 1.8 & 113 & 2663 & 13.8 & 5.6 \\
\hline 27 & 286 & 3.43 & 8.1 & 2.0 & 122 & 2142 & 24.0 & 10.6 \\
\hline 28 & 294 & 3.84 & 20.6 & 2.4 & 113 & 1718 & 31.3 & 15.3 \\
\hline 29 & 298 & 3.96 & 33.8 & 2.7 & 101 & 745 & 51.1 & 34.3 \\
\hline 30 & 305 & 3.95 & 33.0 & 4.1 & 131 & 3144 & 17.8 & 5.2 \\
\hline 31 & 311 & 3.92 & 33.5 & 2.8 & 117 & 1008 & 53.9 & 32.2 \\
\hline 32 & 325 & 3.98 & 47.3 & 4 & 104 & 767 & 36.3 & 15.4 \\
\hline 33 & 325 & 6.09 & 61.6 & 6.3 & 105 & 679 & 42.1 & 22.7 \\
\hline 34 & 328 & 4.53 & 45.9 & 5.3 & 108 & 910 & 36.9 & 17.5 \\
\hline 35 & 331 & 4.35 & 44.0 & 4.2 & 104 & 942 & 30.5 & 10.7 \\
\hline
\end{tabular}

The total number of species observed was 508, whereas the Chao2 estimate of true species richness gave $627 \pm 28($ mean \pm SD). These estimates showed little sign of approaching asymptotic values (Fig. 3). The polychaetes (250 species) constituted $49 \%$ of the total number of species, whereas the molluscs (109 species), crustaceans (95 species), and echinoderms (26 species) comprised 21, 19 and 5\%, respectively (Fig. 4). The total number of individuals was 35376 .

\section{Abundance and species range sizes}

Maximum dominance of a single species across the whole data set was $9.9 \%$ (for Euchone incolor), and the tenth most dominant species comprised $2.0 \%$ 
Table 2. Local abundance of the most dominant species per $0.5 \mathrm{~m}^{2}$. Sites ordered in sequence from shallow to deep water. ${ }^{*}$ Highest dominance within a single site $(42.4 \%)$

\begin{tabular}{|c|c|c|c|c|c|}
\hline Site & $\begin{array}{l}\text { Euchone } \\
\text { incolor }\end{array}$ & $\begin{array}{c}\text { Myriochele } \\
\text { oculata }\end{array}$ & $\begin{array}{l}\text { Amythasides } \\
\text { macroglossus }\end{array}$ & $\begin{array}{c}\text { Limatula } \\
\text { subauriculata }\end{array}$ & $\begin{array}{l}\text { Owenia } \\
\text { fusiformis }\end{array}$ \\
\hline 1 & 0 & 26 & 0 & 49 & 103 \\
\hline 2 & 0 & 11 & 3 & 12 & 30 \\
\hline 3 & 9 & 258 & 23 & 2 & 87 \\
\hline 4 & 17 & 227 & 68 & 0 & 233 \\
\hline 5 & 11 & 45 & 66 & 3 & 83 \\
\hline 6 & 0 & 2 & 0 & 163 & 8 \\
\hline 7 & 0 & 7 & 0 & 0 & 81 \\
\hline 8 & 3 & 185 & 3 & 0 & 144 \\
\hline 9 & 0 & 0 & 4 & 123 & 8 \\
\hline 10 & 0 & 0 & 5 & 235 & 6 \\
\hline 11 & 0 & 17 & 1 & 36 & 10 \\
\hline 12 & 1 & 10 & 24 & 238 & 6 \\
\hline 13 & 2 & 14 & 0 & 159 & 9 \\
\hline 14 & 18 & 3 & 0 & 53 & 31 \\
\hline 15 & 106 & 48 & 0 & 7 & 133 \\
\hline 16 & 1 & 4 & 0 & 0 & 106 \\
\hline 17 & 0 & 4 & 5 & 244 & 29 \\
\hline 18 & 1 & 98 & 6 & 1 & 46 \\
\hline 19 & 0 & 2 & 0 & 26 & 2 \\
\hline 20 & 0 & 11 & 4 & 162 & 18 \\
\hline 21 & 1 & 8 & 6 & 238 & 10 \\
\hline 22 & 19 & 57 & 5 & 3 & 23 \\
\hline 23 & 114 & 55 & 286 & 0 & 6 \\
\hline 24 & 5 & 15 & 18 & 0 & 1 \\
\hline 25 & 199 & 161 & 241 & 1 & 1 \\
\hline 26 & 421 & 969 & 287 & 0 & 36 \\
\hline 27 & 295 & 42 & 355 & 0 & 9 \\
\hline 28 & 206 & 161 & 294 & 0 & 2 \\
\hline 29 & 52 & 8 & 16 & 0 & 0 \\
\hline 30 & $1332^{*}$ & 10 & 100 & 2 & 1 \\
\hline 31 & 113 & 11 & 29 & 0 & 0 \\
\hline 32 & 62 & 4 & 0 & 0 & 158 \\
\hline 33 & 92 & 30 & 0 & 0 & 0 \\
\hline 34 & 159 & 2 & 10 & 0 & 0 \\
\hline 35 & 259 & 38 & 0 & 0 & 0 \\
\hline
\end{tabular}

(Table 4). The cumulative dominance of the 10 most abundant species in the area was $44.3 \%$. Maximum dominance within a site ranged from 7.0 to $42.4 \%$. Local abundance of $E$. incolor was positively related to a range of environmental variables, notably siltclay content, median grain size and depth (Table 3). Conversely, abundance of the mollusc Limatula subauriculata (fourth most abundant species: see Table 4) and Owenia fusiformis (fifth) was negatively correlated with a number of environmental variables, notably median grain size and depth, respectively (Table 3 ). The local abundance of Myriochele oculata (second most abundant) and Amythasides macroglossus (third) showed no relationship to measured environmental factors (Table 3).

Species range size within the study area was positively related to local abundance of the dominant taxonomic groups (Table 5). Only 3 species spanned the whole sampling area of 35 sites, 5 species were represented at all but 1 site, and 1 was found at all but 2 sites (Fig. 5). These widespread species, dominated by polychaetes, were among the 19 most abundant. Conversely, 129 species, or $25 \%$ of the total number of species, were uniques (restricted to a single site), and 70 species $(14 \%)$ were restricted to only 2 sites (duplicates; Fig. 5). The uniques had low abundances: 106 species (82\%) were singletons (only 1 individual at a site) and 14 species $(11 \%)$ were doubletons (2 individuals). Only $23 \%$ of the total number of polychaetes were found at 1 single site; $26 \%$ of the mol-

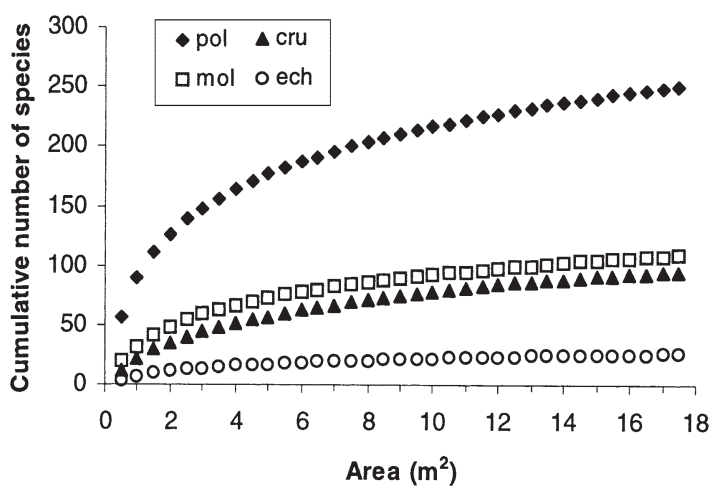

Fig. 4. Cumulative number of species plotted against area $\left(\mathrm{m}^{2}\right)$ within dominant taxonomic groups. Plotted values are means of 50 estimates based on 50 randomisations of sample accumulation order (without replacement). pol: polychaetes; mol: molluscs; cru: crustaceans; ech: echinoderms

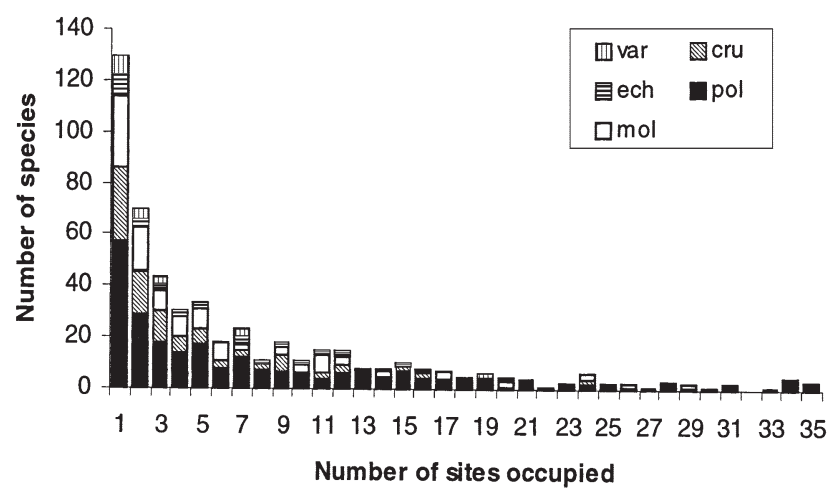

Fig. 5. Distribution of species range sizes within taxonomic groups. Range size is the number of sites occupied by a species out of a total of 35 sites (cf. Fig. 1). pol: polychaetes; cru: crustaceans; mol: molluscs; ech: echinoderms; var: varia (other species) 
Table 3. Pairwise Spearman rank correlations between environmental and biotic variables, with significant ( $p<0.01)$ coefficients in bold face ( $\mathrm{n}$ for all correlations $=35$ ). Md $\varphi$ : median grain size; Silt-clay: fraction of sediment $<0.063 \mathrm{~mm}(\%)$; TOM: total organic matter $(\%) ; S k_{I}$ : skewness; $\sigma_{I}$ : sorting. Tot: total (all taxa pooled); Pol: polychaetes; Mol: molluscs; Cru: crustaceans; Ech: echinoderms. S: number of species; ExpH': exponentiated form of the Shannon formula; 1/SI: reciprocal of Simpson's index; Uniques: species restricted to a single site; Singletons: species represented by a single individual; N: local abundance of the most dominant species (cf. Table 2)

\begin{tabular}{|c|c|c|c|c|c|c|c|c|}
\hline & Latitude & Longitude & Depth (m) & $\operatorname{Md} \varphi$ & Silt-clay & TOM & $S k_{I}$ & $\sigma_{I}$ \\
\hline Longitude & -0.22 & & & & & & & \\
\hline Depth (m) & 0.82 & 0.22 & & & & & & \\
\hline $\operatorname{Md} \varphi$ & 0.60 & 0.40 & 0.85 & & & & & \\
\hline Silt-clay & 0.60 & 0.28 & 0.75 & 0.72 & & & & \\
\hline TOM & 0.70 & 0.28 & 0.77 & 0.60 & 0.81 & & & \\
\hline$S k_{I}$ & 0.23 & -0.04 & 0.25 & 0.08 & 0.56 & 0.35 & & \\
\hline$\sigma_{\mathrm{I}}$ & 0.46 & 0.18 & 0.56 & 0.60 & 0.91 & 0.68 & 0.54 & \\
\hline Tot S & 0.39 & 0.08 & 0.27 & 0.11 & 0.49 & 0.60 & 0.63 & 0.42 \\
\hline Tot $\operatorname{Exp} H^{\prime}$ & -0.02 & 0.21 & -0.01 & -0.02 & 0.18 & 0.11 & 0.16 & 0.13 \\
\hline Tot 1/SI & -0.06 & 0.14 & -0.05 & -0.02 & 0.09 & -0.02 & 0.09 & 0.04 \\
\hline Pol S & 0.29 & 0.15 & 0.27 & 0.21 & 0.56 & 0.53 & 0.60 & 0.49 \\
\hline Pol Exp $H^{\prime}$ & -0.06 & 0.13 & -0.14 & -0.25 & -0.18 & -0.00 & -0.21 & -0.27 \\
\hline Pol 1/SI & -0.08 & 0.08 & -0.17 & -0.25 & -0.25 & -0.10 & -0.21 & -0.34 \\
\hline Mol S & 0.50 & -0.08 & 0.44 & 0.26 & 0.51 & 0.55 & 0.65 & 0.46 \\
\hline Mol Exp $H^{\prime}$ & 0.42 & 0.20 & 0.52 & 0.60 & 0.64 & 0.49 & 0.45 & 0.63 \\
\hline Mol 1/SI & 0.38 & 0.20 & 0.47 & 0.57 & 0.60 & 0.42 & 0.37 & 0.60 \\
\hline Cru S & 0.36 & 0.06 & 0.18 & -0.01 & 0.26 & 0.49 & 0.34 & 0.19 \\
\hline Cru $\operatorname{Exp} H^{t}$ & 0.39 & -0.18 & 0.11 & -0.08 & 0.11 & 0.36 & 0.10 & 0.11 \\
\hline Cru 1/SI & 0.31 & -0.31 & 0.03 & -0.16 & -0.01 & 0.23 & -0.03 & 0.05 \\
\hline Ech S & -0.17 & 0.01 & -0.17 & -0.25 & -0.04 & -0.02 & 0.25 & -0.00 \\
\hline Ech $\operatorname{Exp} H^{\prime}$ & -0.12 & 0.03 & -0.11 & -0.22 & 0.05 & 0.06 & 0.39 & 0.08 \\
\hline Ech 1/SI & -0.14 & 0.04 & -0.13 & -0.25 & 0.04 & 0.03 & 0.41 & 0.08 \\
\hline Uniques & -0.02 & -0.03 & -0.20 & -0.29 & 0.03 & 0.04 & 0.22 & -0.02 \\
\hline Singletons & 0.12 & 0.06 & -0.02 & -0.15 & 0.17 & 0.32 & 0.26 & 0.12 \\
\hline Euchone incolor $\mathrm{N}$ & 0.60 & 0.05 & 0.70 & 0.71 & 0.72 & 0.50 & 0.56 & 0.67 \\
\hline Myriocheleoculata N & -0.04 & -0.06 & 0.00 & 0.18 & 0.00 & -0.10 & 0.14 & 0.06 \\
\hline Amythasides macroglossus $\mathrm{N}$ & 0.24 & -0.02 & 0.23 & 0.29 & 0.08 & 0.12 & 0.29 & 0.04 \\
\hline Limatuala subauriculata N & -0.26 & -0.10 & -0.50 & -0.65 & -0.46 & -0.17 & -0.18 & -0.41 \\
\hline Owenia fusiformis $\mathrm{N}$ & -0.59 & -0.28 & -0.60 & -0.50 & -0.43 & -0.58 & -0.08 & -0.24 \\
\hline
\end{tabular}

luscs were uniques; whereas up to $31 \%$ of both the crustaceans and echinoderms were uniques. There was a positive correlation between local species richness and singletons (Spearman's $\mathrm{R}_{\mathrm{s}}=0.69, \mathrm{p}<0.001$, $\mathrm{n}=35)$ and uniques $\left(\mathrm{R}_{\mathrm{s}}=0.44, \mathrm{p}=0.007, \mathrm{n}=35\right)$, although the latter explained less of the variance. The number of singletons and the number of uniques per site were positively correlated $\left(R_{s}=0.49, p=0.003, n=35\right)$, but neither was related to measured environmental variables (Table 3).

\section{Beta diversity}

Whittaker's $\beta_{W}$ varied between the dominant taxonomic groups, and was highest for crustaceans (6.5), followed by echinoderms (5.5), molluscs (4.6) and polychaetes (3.2), whereas $\beta_{W}$ for all taxonomic groups pooled was 4.0
(Fig. 6). Cumulative $\beta_{W}$ for crustaceans and echinoderms increased markedly when the 13 deepest sites (Table 1) were included, whereas $\beta_{W}$ for polychaetes and molluscs did not (Fig. 6). Twenty-six percent of the crustaceans (25 species) and $23 \%$ of the echinoderms (5 species) were only found at these deeper sites,

Table 4. Dominance patterns across the whole data set

\begin{tabular}{|lccc|}
\hline Species & $\begin{array}{c}\text { No. of } \\
\text { individuals }\end{array}$ & $\begin{array}{c}\text { Dominance } \\
(\%)\end{array}$ & $\begin{array}{c}\text { Cumulative } \\
\text { dominance (\%) }\end{array}$ \\
\hline Euchone incolor & 3498 & 9.89 & 9.89 \\
Myriochele oculata & 2543 & 7.19 & 17.08 \\
Amythasides macroglossus & 1859 & 5.25 & 22.33 \\
Limatula subauriculata & 1757 & 4.97 & 27.30 \\
Owenia fusiformis & 1420 & 4.01 & 31.31 \\
Notomastus spp. & 1373 & 3.88 & 35.19 \\
Thyasira succisa & 1008 & 2.85 & 38.04 \\
Aonides paucibranchiata & 806 & 2.28 & 40.32 \\
Prionospio multibranchiata & 708 & 2.00 & 42.32 \\
Thyasira obsoleta & 704 & 1.99 & 44.31 \\
\hline
\end{tabular}


Table 5. Interspecific relationships between local abundance and range size within dominant taxonomic groups. Local species abundance values were averaged across space including only non-zero counts. Measure of correlation is Spearman rank correlation (all coefficients were significant at $\mathrm{p}<0.001$ )

\begin{tabular}{|lcc|}
\hline Taxonomic group & $\mathrm{n}$ & $\begin{array}{c}\text { Local abundance } \\
\text { vs range size, } \mathrm{R}_{\mathrm{s}}\end{array}$ \\
\hline Polychaeta & 250 & 0.75 \\
Mollusca & 109 & 0.72 \\
Crustacea & 95 & 0.58 \\
Echinodermata & 26 & 0.76 \\
\hline
\end{tabular}

whereas the relative proportions of new molluscs (19 species) and polychaetes (34 species) in this deeper area were lower (17 and $14 \%$, respectively).

For all pairwise combinations of sites the number of shared species varied between 17 and 84, the complementarity values showed highly variable levels of distinctness (44 to $90 \%$ ), and the Bray-Curtis similarities ranged from 14 to $74 \%$ (Fig. 7). These

Table 6. Measures of beta diversity related to distance and change in environment between all pairwise combinations of sites. Measure of correlation is the product-moment correlation, r. $V_{j \mathrm{k}}$ : number of species shared; $C_{j \mathrm{k}}$ : complementarity or biotic distinctness (\%); B-C: Bray-Curtis similarity (\%). Tot: total (all taxa pooled); Pol: polychaetes; Mol: molluscs; Cru: crustaceans; Ech: echinoderms. Md $\varphi$ : median grain size; Silt-clay: fraction of sediment $<0.063 \mathrm{~mm} \mathrm{( \% );} \mathrm{TOM:}$ total organic matter (\%); $\sigma_{I}$ : sorting. (a) All 35 sites, all coefficients were significant at $\mathrm{p}<0.001, \mathrm{n}$ for all correlations $=595$; (b) 17 shallowest sites in the study area (cf. Table 1), significant coefficients $\left({ }^{*} p<0.05 ;{ }^{* *} p<0.001\right)$ in bold face ( $\mathrm{n}$ for all correlations $=136$ )

\begin{tabular}{|lrrrrrr|}
\hline $\begin{array}{l}\text { Beta diversity } \\
\text { measure }\end{array}$ & $\begin{array}{c}\text { Distance } \\
(\mathrm{km})\end{array}$ & $\begin{array}{c}\text { Depth } \\
(\mathrm{m})\end{array}$ & $\mathrm{Md} \varphi$ & Silt-clay & TOM & $\sigma_{I}$ \\
\hline a (35 sites) & & & & & & \\
Tot $V_{j k}$ & -0.41 & -0.55 & -0.49 & -0.42 & -0.31 & -0.40 \\
Tot $C_{j k}$ & 0.41 & 0.67 & 0.65 & 0.55 & 0.41 & 0.46 \\
Tot B-C & -0.40 & -0.69 & -0.67 & -0.60 & -0.44 & -0.49 \\
Pol $V_{j k}$ & -0.36 & -0.42 & -0.39 & -0.31 & -0.26 & -0.33 \\
Pol $C_{j k}$ & 0.34 & 0.54 & 0.52 & 0.43 & 0.34 & 0.40 \\
Pol B-C & -0.37 & -0.64 & -0.60 & -0.53 & -0.39 & -0.47 \\
Mol $V_{j k}$ & -0.39 & -0.53 & -0.49 & -0.42 & -0.31 & -0.35 \\
Mol $C_{j k}$ & 0.40 & 0.65 & 0.63 & 0.55 & 0.40 & 0.41 \\
Mol B-C & -0.38 & -0.62 & -0.64 & -0.61 & -0.50 & -0.39 \\
Cru $V_{j k}$ & -0.27 & -0.45 & -0.39 & -0.36 & -0.23 & -0.29 \\
Cru $C_{j k}$ & 0.29 & 0.54 & 0.53 & 0.47 & 0.31 & 0.34 \\
Cru B-C & -0.29 & -0.57 & -0.57 & -0.50 & -0.32 & -0.38 \\
Ech $V_{j k}$ & -0.22 & -0.35 & -0.29 & -0.35 & -0.29 & -0.26 \\
Ech $C_{j k}$ & 0.24 & 0.34 & 0.31 & 0.34 & 0.29 & 0.25 \\
Ech B-C & -0.25 & -0.36 & -0.33 & -0.36 & -0.34 & -0.25 \\
b (17 sites) & & & & & & \\
Tot $V_{j k}$ & $-\mathbf{0 . 3 6 * *}$ & -0.00 & -0.06 & 0.04 & 0.02 & 0.00 \\
Tot $C_{j k}$ & $\mathbf{0 . 3 5 * *}$ & -0.06 & $\mathbf{0 . 2 0}$ & 0.02 & $\mathbf{0 . 2 2}{ }^{*}$ & 0.01 \\
Tot B-C & $-\mathbf{0 . 3 0 * *}$ & 0.04 & -0.12 & -0.03 & -0.16 & -0.04 \\
& & & & & & \\
\hline
\end{tabular}

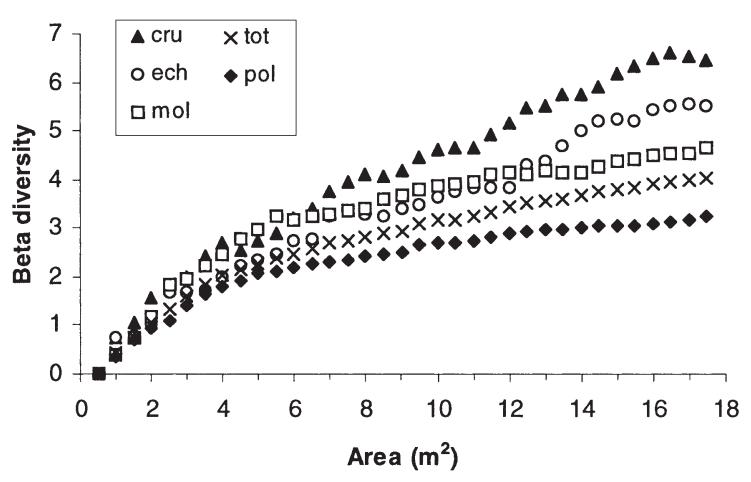

Fig. 6. Cumulative beta diversity $\left(\beta_{W}\right)$ plotted against area $\left(\mathrm{m}^{2}\right)$ within dominant taxonomic groups and for all taxa pooled. Samples ordered in sequence from shallow to deep water. pol: polychaetes; cru: crustaceans; mol: molluscs; ech: echinoderms; tot: total (all taxa pooled)

measures of $\beta$ diversity were closely related to change in environmental variables, notably depth (Fig. 7), followed by median grain size and silt-clay content, whereas, surprisingly, spatial distance between sites showed a lower relationship (Table 6a). Thus, sites located at the same depth (or with similar median grain size or siltclay content) shared significantly more species, had lower biotic distinctness and were more similar on average than sites located at different depths (or with different median grain size or silt-clay content). The Bray-Curtis similarity, followed by the complementarity, was in general more related to environmental variables than the number of shared species. Relationships between $\beta$ diversity and change in environmental variables varied between taxonomic groups (Table 6a). Generally, $\beta$ diversity measures for molluscs were closely related to environmental variables, notably depth and median grain size, and polychaetes were more closely related to environmental factors than crustaceans and echinoderms. Based on only the 17 shallowest sites (i.e. depth differences $\leq 45 \mathrm{~m}$ ), where the variability in sediment characteristics was smaller than in the whole area (see Table 1), the relationships between $\beta$ diversity and environmental variables were either weak or not significant (Table 6a). 
Faunal assemblages in space

Clustering, based on Bray-Curtis similarities from square-root-transformed abundances, took place over a wide range of similarities, and the MDS-ordination shows that the faunal patterns changed across the study area (Figs. 1 \& 8). The multivariate analyses gave additional information to the univariate measures of community structure. Three main groups were identified (Groups A to C), although the average similarity within each group was low $(52,50$ and $48 \%$, respectively). Group A comprised 12 of the 13 deepest sites in the area, of which the 7 deepest sites (range 298 to $331 \mathrm{~m}$ ) were separated as a subgroup (A1). Groups B and $C$ comprised sites that were relatively widely separated both geographically and in terms of depth. Site Nos. 19 and 7 were separated from Groups B and C, respectively. These sites had the lowest number of species and individuals in the study area (Table 1). Euchone incolor and Amythasides macroglossus were the most dominant species within Group A and Limatula subauriculata within B, whereas Owenia fusiformis and Myriochele oculata had the highest average abundance in C. These dominant species (Table 2) also contributed much to the dissimilarities between the 3 main groups.

The rank correlations between single environmental factors and square-root-transformed abundance data (BIO-ENV analysis) ranged from 0.03 to 0.69 (Table 7). Water depth showed the highest degree of correlation with the faunal composition, followed by median grain size and silt-clay content. The subset of environmental variables which best 'explained' the faunal patterns includes depth, median grain size and silt-clay content $\left(R_{S}=0.76\right)$. Relationships between environmental vari-
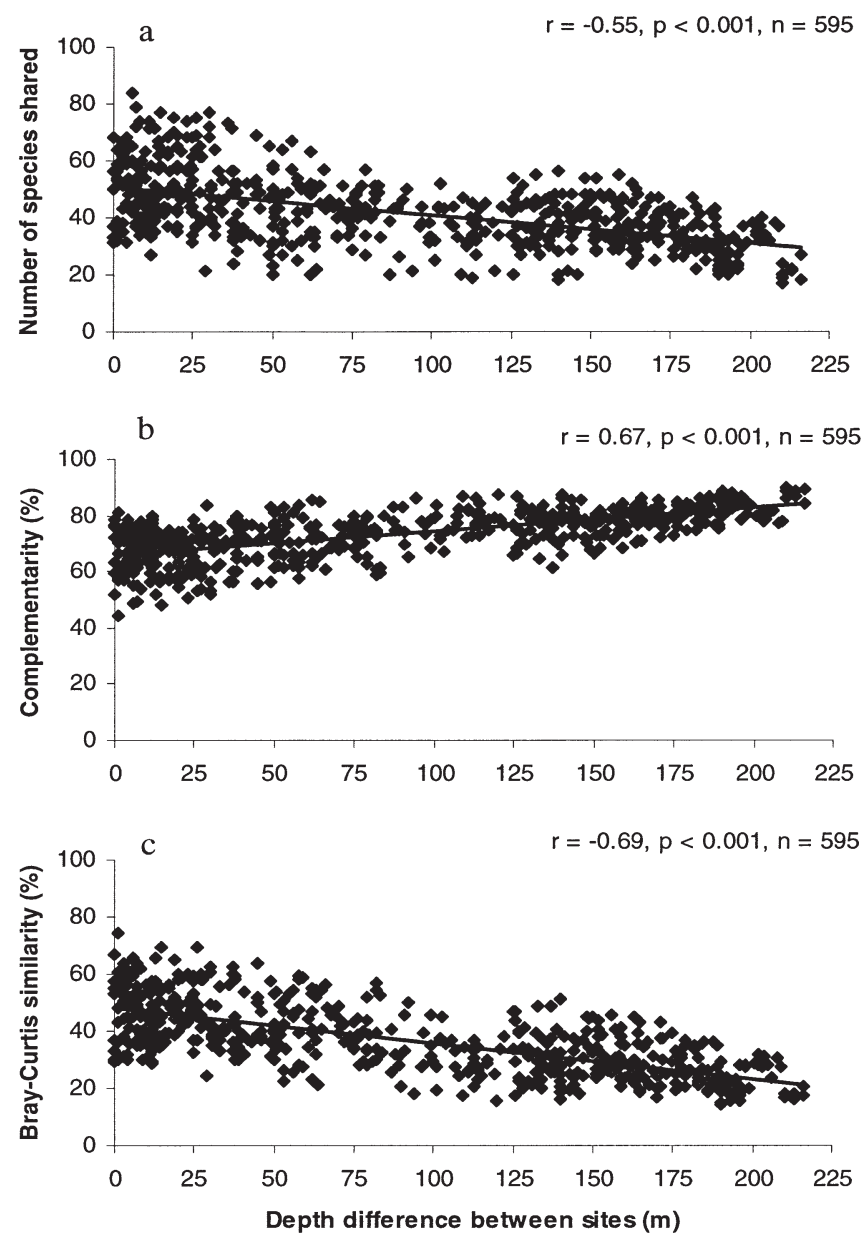

Fig. 7. Measures of beta diversity related to depth difference between sites for all pairwise combinations of 35 sites. Measure of correlation is the product-moment correlation coefficient, r. (a) Number of species shared; (b) complementarity or biotic distinctness; (c) Bray-Curtis similarity

Table 7. Summary of results from BIO-ENV analyses of 35 sites for all taxa pooled and for the dominant taxonomic groups, and for Groups B and C from the cluster analysis (23 sites, cf. Fig. 8a). Spearman rank correlations $\left(\mathrm{R}_{\mathrm{s}}\right)$ between biotic and abiotic similarity matrices, with highest correlations in bold face. Lower correlations are omitted from the table. Biotic data square-roottransformed, abiotic data $\log (1+n)$ transformed with the exception of latitude, longitude and depth. Md $\varphi$ : median grain size; Siltclay: fraction of sediment $<0.063 \mathrm{~mm}(\%)_{i}$ TOM: total organic matter $(\%)_{i} S k_{I}$ : skewness; $\sigma_{I}$ : sorting; Lat: latitude; Long: longitude

\begin{tabular}{|c|c|c|c|c|c|}
\hline Total & Polychaeta & Mollusca & Crustacea & Echinodermata & $\begin{array}{l}\text { Groups B and C } \\
\text { Total }\end{array}$ \\
\hline Depth (0.69) & Depth (0.63) & $\operatorname{Md} \varphi(\mathbf{0 . 6 3})$ & Depth (0.59) & Depth (0.36) & $\operatorname{Md} \varphi(\mathbf{0 . 2 5})$ \\
\hline $\operatorname{Md} \varphi(0.68)$ & $\operatorname{Md} \varphi(0.60)$ & Depth (0.61) & $\operatorname{Md} \varphi(0.58)$ & Silt-clay (0.32) & Lat $(0.20)$ \\
\hline Silt-clay (0.53) & Silt-clay (0.49) & TOM (0.48) & Silt-clay $(0.41)$ & TOM (0.31) & Depth $(0.14)$ \\
\hline$\sigma_{I}(0.48)$ & $\sigma_{I}(0.46)$ & Silt-clay (0.48) & $\sigma_{I}(0.36)$ & $\operatorname{Md} \varphi(0.29)$ & $S k_{I}(0.10)$ \\
\hline TOM $(0.44)$ & TOM (0.37) & $\sigma_{I}(0.38)$ & TOM (0.32) & Lat $(0.24)$ & Long $(0.07)$ \\
\hline Lat $(0.34)$ & Lat $(0.31)$ & Lat $(0.33)$ & Lat $(0.20)$ & $\sigma_{I}(0.21)$ & TOM (0.06) \\
\hline$S k_{I}(0.09)$ & $S k_{I}(0.07)$ & $S k_{I}(0.15)$ & $S k_{I}(0.16)$ & $S k_{I}(0.14)$ & $\sigma_{I}(0.02)$ \\
\hline Long (0.03) & Long $(0.00)$ & Long (0.02) & Long (0.07) & Long (0.05) & Silt-clay $(-0.02)$ \\
\hline $\begin{array}{l}\text { Max. corr.: } \\
\text { Depth, Md } \varphi \text {, } \\
\text { Silt-clay } \mathbf{( 0 . 7 6 )}\end{array}$ & $\begin{array}{l}\text { Max. corr.: } \\
\text { Depth, Md } \varphi, \\
\text { Silt-clay (0.68) }\end{array}$ & $\begin{array}{l}\text { Max. corr.: } \\
\text { Depth, Md } \varphi_{1} S k_{I_{1}} \\
\text { TOM (0.72) }\end{array}$ & $\begin{array}{l}\text { Max. corr.: } \\
\text { Depth, Md } \varphi, \\
\text { Silt-clay } \mathbf{( 0 . 6 4 )}\end{array}$ & $\begin{array}{l}\text { Max. corr.: Lat, } \\
\text { Depth, Md } \varphi \text {, Silt-clay, } \\
S_{k_{I I}} \text { TOM (0.42) }\end{array}$ & $\begin{array}{l}\text { Max. corr.: Lat, Long, } \\
\text { Depth, Md } \varphi_{1} S k_{I_{r}} \\
\text { TOM (0.32) }\end{array}$ \\
\hline
\end{tabular}




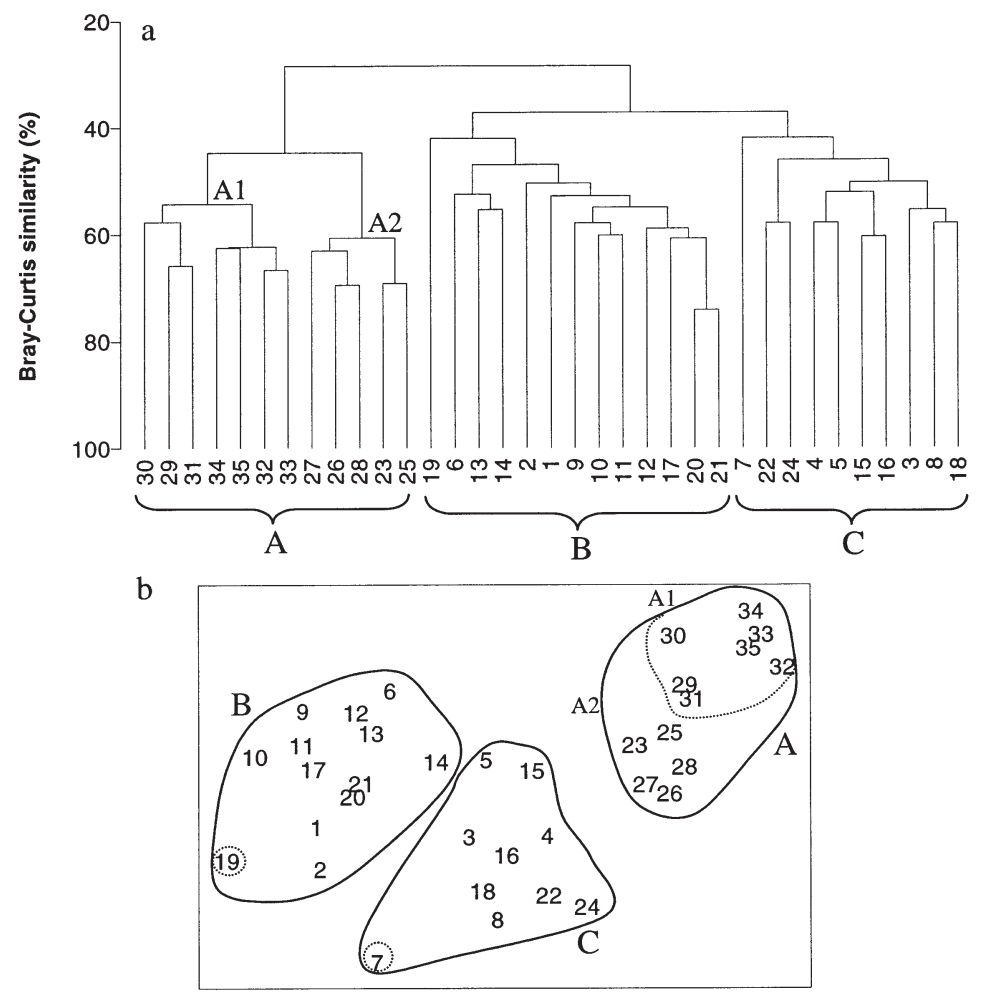

Fig. 8. (a) Hierarchical, agglomerative clustering of square-root-transformed macrobenthos data using group-average linking on Bray-Curtis similarities (\%); (b) multidimensional scaling ordination for square-roottransformed macrobenthos data based on Bray-Curtis similarities (stress $=0.10)$

ables and faunal patterns varied between the dominant taxonomic groups (Table 7). The patterns of molluscs, followed by polychaetes, were more strongly related to subsets of environmental factors than crustaceans and echinoderms, and depth and median grain size showed the highest degree of correlation with the faunal patterns. Based on only Groups B and C from the clustering (i.e. less environmental variability than for the whole area; see Fig 8 and Table 1) the relationships between individual environmental factors and biotic patterns were weaker $\left(\mathrm{R}_{\mathrm{s}}\right.$ : -0.02 to 0.25 : Table 7$)$. The correlations between the faunal composition and different subsets of environmental factors were also low for this data set $\left(R_{s} \leq 0.32\right.$ : Table 7$)$.

\section{DISCUSSION}

\section{Alpha and gamma diversity}

In this study, covering $2700 \mathrm{~km}^{2}, 22$ of 35 sites contained more than 100 species, whereas in a single softsediment habitat type, covering $9100 \mathrm{~km}^{2}$, in the south- ern part of the Norwegian continental shelf, Ellingsen (2001) found that the highest local $\left(0.5 \mathrm{~m}^{2}\right)$ richness was 81 species. The total richness in the present study was 508 species and the number of individuals 35376. Ellingsen found that 16 sites comprised 175 species and 9243 individuals. For a similar number of individuals (9684) in this study, 10 sites provided 343 species, whereas 16 sites comprised 404 species and 16247 individuals (based on 50 randomisations). Thus, both $\alpha$ and $\gamma$ diversity increased with increasing environmental variability, and the largest area was not richer than the other area. According to Rosenzweig (1995), the greater the habitat variety, the greater the species diversity.

The polychaete Euchone incolor (Sabellidae), which had the highest dominance across the whole area, was represented by as much as 1332 individuals at Site 30, and the heterogeneity diversity at this site was therefore among the lowest. The fact that this site also had the highest species richness (131 species) suggests that 'tube lawns' of polychaetes may have positive influence on benthic ecosystems, presumably by increasing sediment heterogeneity. Furthermore, these data show that no single measure can describe $\alpha$ diversity.

Univariate diversity measures of molluscs, followed by polychaetes, were generally more highly correlated with environmental variables than the other dominant taxonomic groups, and only molluscs were related to depth and median grain size. In a field manipulation experiment, Wu \& Shin (1997) found that bivalves and gastropods exhibited preference in their colonisation for sand or mud, whereas polychaetes and amphipods did not.

Neither the species accumulation curve nor the Chao2 estimate of true species richness reached asymptotic values, and the Chao 2 value was almost certainly an underestimate. The number of slightly different patches will increase with increasing sampling area in soft sediments because of small-scale spatial variability, and species accumulation curves are therefore unlikely to reach asymptotic values. Ellingsen (2001) found that even in a relatively uniform soft-sediment habitat (16 sites) these estimates showed no sign of stabilising towards asymptotes. For the present study area none of the estimates Chao1, Jackknife1 and Jackknife2 (Colwell \& Coddington 1994) reached asymptotic values (data not shown). In a terrestrial study involving 34 species, Colwell \& Coddington (1994) showed that as few as 12 samples provided a useful Chao2 estimate, and Jackknife2 gave the second-best estimate. Differences between Colwell $\&$ Coddington's data and the present study may be due 
to the different number of species involved in the studies. Differences between marine and terrestrial studies may also be due to methodology and what constitutes a sample in the respective environments (Paterson et al. 1998). Furthermore, species of low local abundance, regardless of the number of sites at which they occur, have a low probability of being recorded (Brown 1984, Gaston 1994). With insufficient sampling intensity, species may appear to occur at fewer sites and/or have lower abundance.

\section{Distributions of species}

The finding, in this study, that common species were widely spatially distributed, whereas species of low abundance had strongly compressed range sizes, holds true for many different groups of species over a variety of habitat types and spatial scales and appears to be general (Brown 1984). Polychaetes were the most common taxonomic group and had the highest proportion of widespread species, whereas crustaceans and echinoderms were more restricted in their distributions than the other dominant groups. Moreover, the group of restricted-range species (uniques and duplicates) comprised a significant fraction of the benthos (39\%). As Ellingsen (2001) found similar patterns in a relatively homogeneous habitat, the above findings may be general for marine benthos.

Ellingsen (2001) showed that sites of high species richness were those rich in restricted-range species. This does not always hold true in marine systems (Schlacher et al. 1998), and in the present study local species richness was only weakly related to the number of uniques. The selection of a limited number of species-rich areas will therefore not guarantee effective conservation of restricted-range species, because a large proportion of them may occur outside the species-rich areas. The loss of marine habitats caused by a variety of human activities is great in coastal areas. Species with restricted range and which occur in few habitats are usually the most vulnerable to environmental change (Thomas \& Mallorie 1985). The most effective way to conserve biodiversity is to prevent the conversion or degradation of habitats (Heywood \& Watson 1995, p. 920).

\section{Beta diversity and relationships to range size, environmental variability and distance}

Studies of $\beta$ diversity gave much additional information to that of $\alpha$ and $\gamma$ diversity. Whittaker's $(1960,1972)$ beta diversity $\left(\beta_{W}\right)$ was highest for crustaceans, followed by echinoderms, molluscs and polychaetes (range 3.2 to 6.5). Ellingsen (2001) found lower $\beta_{W}$ values (1.0 to 2.3) for these groups in a single habitat type. This suggests that within taxonomic groups $\beta$ diversity will increase with increasing environmental dissimilarity between sites. $\beta_{W}$ was highest for those taxonomic groups with the highest proportion of restricted-range species, a relationship that was also found in Ellingsen's study. Cumulative $\beta_{W}$ for crustaceans and echinoderms increased significantly when the deepest sites in the study area were included (Fig. 6), due to the fact that a relatively large proportion of these groups were found only at these deeper sites.

The number of shared species, complementarity, and the Bray-Curtis similarity between all pairwise permutations of sites showed that $\beta$ diversity was higher in the present study than in Ellingsen's (2001) study. Moreover, the degree of faunal dissimilarity was highest in the present study. However, there are, as yet, few studies that can be used as a comparison, and we do not know enough about $\beta$ diversity in the sea to decide what is a high value and what is a low value. Change in environment, notably depth followed by median grain size and silt-clay content, had a stronger effect on $\beta$ diversity, especially Bray-Curtis similarity, than spatial distance between sites in this study. Likewise, a BIOENV analysis (Table 7) identified depth, median grain size and silt-clay content as the major environmental variables influencing the faunal patterns, whereas univariate measures of diversity were not related to depth or median grain size. However, the relationships to environmental variables were weaker with less environmental variability (i.e. when the deepest sites were excluded, see Tables $6 \mathrm{~b} \&$ 7). Likewise, Ellingsen found weak relationships between environmental variables and faunal composition. Surprisingly, Schlacher et al. (1998) found no clear relationships between environmental factors and biotic assemblages in a coral lagoon even though there was considerable variation in sediment characteristics. Regardless of the strength of a relationship, correlations do not imply causality, and it is probable that factors other than those measured may have influenced the community structure. Biotic factors such as availability and abundance of benthic larvae/ adults may be more important than sediment characteristics in determining benthic settlement (Wu \& Shin 1997). No single mechanism has been able to explain faunal patterns observed across many different environments, and it seems likely that, at any given location, a number of different interacting factors will be involved (Snelgrove \& Butman 1994, Mackie et al. 1997). The finding that $\beta$ diversity measures of molluscs, followed by polychaetes, were more strongly related to environmental variables than crustaceans and echinoderms is in accordance with both the univariate measures of diversity and the BIO-ENV analyses 
(Tables 6a \& 7). Olsgard \& Somerfield (2000) found that faunal patterns of polychaetes had stronger relationships to environmental variables than those of the other dominant taxonomic groups.

Ellingsen (2001) showed that the Bray-Curtis similarity between all combinations of sites was weakly related to distance, whereas the number of shared species and the complementarity were independent of spatial distance. Likewise, in a study of soft-sediment fauna in a coral lagoon Schlacher et al. (1998) found that the number of shared species between all pairwise permutations of sites was low, but weakly correlated with distance. At a larger scale, Paterson et al. (1998) found in the Atlantic and Pacific that changes in polychaete composition (species turnover) was related to distance. Likewise, Clarke \& Lidgard (2000) showed that bryozoan species turnover in the North Atlantic was a function of distance. However, distance between sites may be associated with differences in environmental variables, confounding the interpretation of distance effects (Harrison et al. 1992). Price et al. (1999) found that $\beta$ diversity for asteroids was highest in shelf regions and lowest in lower bathyal/abyssal regions in the Atlantic Ocean. They suggested that this finding reflected the greater heterogeneity of habitats and environmental conditions in coastal areas compared with deeper areas. However, the number of studies that have explored any patterns of $\beta$ diversity is small (Gaston \& Williams 1996), and few marine $\beta$ diversity studies have been undertaken as yet.

\section{Conclusions}

Polychaetes were the most common taxonomic group and had the highest proportion of widespread species, whereas crustaceans and echinoderms were more restricted in their distribution than the other dominant groups. Whittaker's $(1960,1972)$ beta diversity $\left(\beta_{W}\right)$ was highest for those taxonomic groups with the highest proportion of restricted-range species. Changes in environment (notably depth, followed by median grain size and silt-clay content) had a stronger effect on $\beta$ diversity, especially Bray-Curtis similarity, than spatial distance between sites. Likewise, a multivariate analysis (BIO-ENV) identified these factors as the major environmental variables influencing the faunal patterns, whereas univariate measures of diversity were not related to depth or median grain size. Molluscs, followed by polychaetes, were more strongly related to environmental variables than crustaceans and echinoderms. As distributions of species, community differences and relationships to environmental variables varied between the dominant taxonomic groups, more than one group in a system should be studied. Local species richness, distributions of species, community structure and community differences varied greatly within the study area. As it is likely that community structure will vary within any latitudinal area, a comparison of only a few sites between areas may be insufficient.

In this study, alpha, beta and gamma diversity were higher than in Ellingsen's (2001) study of a single habitat type at the southern part of the Norwegian continental shelf. This suggests that measurement of marine biodiversity may be dependent on environmental variability. However, many more studies are needed before any generality can be attached to these findings. Habitat diversity, measured as diversity in environmental variables, may be useful as an indirect measure of biodiversity (Ward et al. 1998). However, in soft-sediment studies, where one is usually sampling blind, spot grab or core samples may give a misleading concept of the spatial scales of different seabed types. New remote acoustic and visual techniques collect continuous data from large areas relatively quickly, and give additional information to traditional point-sampling. A knowledge of relationships between measures of biodiversity and different levels of environmental variability is needed to study latitudinal gradients in marine systems.

Acknowledgements. I thank John S. Gray for fruitful discussions and for critically reading the manuscript, and Frode Olsgard for valuable discussions. Janicke Garmann improved the manuscript. Thanks also to Statoil, Saga Petroleum and Norsk Hydro for allowing me to use the Region IV data in this analysis, and to Det Norske Veritas for preparing the data set.

\section{LITERATURE CITED}

Bray JR, Curtis JT (1957) An ordination of the upland forest communities of southern Wisconsin. Ecol Monogr 27: 325-349

Brown JH (1984) On the relationship between abundance and distribution of species. Am Nat 124:255-279

Chao A (1987) Estimating the population size for capturerecapture data with unequal catchability. Biometrics 43: 783-791

Clarke A, Lidgard S (2000) Spatial patterns of diversity in the sea: bryozoan species richness in the North Atlantic. J Anim Ecol 69:799-814

Clarke KR (1993) Non-parametric multivariate analyses of changes in community structure. Aust J Ecol 18:117-143

Clarke KR, Ainsworth M (1993) A method of linking multivariate community structure to environmental variables. Mar Ecol Prog Ser 92:205-219

Clarke KR, Green RH (1988) Statistical design and analysis for a 'biological effects' study. Mar Ecol Prog Ser 46: 213-226

Clarke KR, Warwick RM (1994) Change in marine communities: an approach to statistical analysis and interpretation. Plymouth Marine Laboratory, Plymouth

Clifford DHT, Stephenson W (1975) An introduction to numerical classification. Academic Press, New York

Colwell RK, Coddington JA (1994) Estimating terrestrial bio- 
diversity through extrapolation. Phil Trans R Soc Lond Ser B 345:101-118

Ellingsen KE (2001) Biodiversity of a continental shelf softsediment macrobenthos community. Mar Ecol Prog Ser 218:1-15

Etter RJ, Grassle JF (1992) Patterns of species diversity in the deep sea as a function of sediment particle size diversity. Nature 360:576-578

Gaston KJ (1994) Rarity. Chapman \& Hall, London

Gaston KJ (1996) What is biodiversity? In: Gaston KJ (ed) Biodiversity: a biology of numbers and difference. Blackwell Science, Oxford, p 1-9

Gaston KJ, Williams PH (1996) Spatial patterns in taxonomic diversity. In: Gaston KJ (ed) Biodiversity: a biology of numbers and difference. Blackwell Science, Oxford, p 202-229

Gray JS (1974) Animal-sediment relationships. Oceanogr Mar Biol Annu Rev 12:223-261

Gray JS (1997) Marine biodiversity: patterns, threats and conservation needs. Biodiv Conserv 6:153-175

Gray JS (2000) The measurement of marine species diversity, with an application to the benthic fauna of the Norwegian continental shelf. J Exp Mar Biol Ecol 250:23-49

Gray JS, Clarke KR, Warwick RM, Hobbs G (1990) Detection of initial effects of pollution on marine benthos: an example from the Ekofisk and Eldfisk oilfields, North Sea. Mar Ecol Prog Ser 66:285-299

Harper JL, Hawksworth DL (1994) Biodiversity: measurement and estimation. Preface. Phil Trans R Soc Lond Ser B 345: 5-12

Harrison S, Ross SJ, Lawton JH (1992) Beta diversity on geographic gradients in Britain. J Anim Ecol 61:151-158

Heip C, Warwick R, d'Ozouville L (1998) A European science plan on marine biodiversity. European Marine and Polar Science (EMaPS), European Science Foundation (ESF), Strasbourg Cedex

Heywood VH, Watson RT (1995) Global biodiversity assessment. Cambridge University Press, Cambridge

Hill MO (1973) Diversity and evenness: a unifying notation and its consequences. Ecology 54:427-432

Kruskal JB, Wish M (1978) Multidimensional scaling. Sage Publications, Beverly Hills

Jensen T, Bakke SM, Gjøs N, Oreld F, Nøland SA (1997) Environmental monitoring of the Tampen area (Region IV) 1996. Det Norske Veritas AS, Oslo

Legendre P, Vaudor A (1991) The R package: multidimensional analysis, spatial analysis. Département de Sciences Biologiques, Université de Montréal

Levin SA (1992) The problem of pattern and scale in ecology. Ecology 73:1943-1967

Mackie ASY, Parmiter C, Tong LKY (1997) Distribution and diversity of Polychaeta in the southern Irish Sea. Bull Mar Sci 60:467-481

Magurran AE (1988) Ecological diversity and its measurement. Croom Helm, London

May RM (1994) Biological diversity: differences between land and sea. Phil Trans R Soc Lond Biol Sci 343:105-111

Olsgard F, Somerfield PJ (2000) Surrogates in marine benthic investigations - which taxonomic unit to target? J Aquat Ecosyst Health 7:251-42

Paterson GLJ, Wilson GDF, Cosson N, Lamont PA (1998) Hessler and Jumars (1974) revisited: abyssal polychaete assemblages from the Atlantic and Pacific. Deep-Sea Res $45: 225-251$

Editorial responsibility: Otto Kinne (Editor),

Oldendorf/Luhe, Germany
Peet RK (1974) The measurement of species diversity. Annu Rev Ecol Syst 5:285-307

Price ARG, Keeling MJ, O'Callaghan CJ (1999) Ocean-scale patterns of 'biodiversity' of Atlantic asteroids determined from taxonomic distinctness and other measures. Biol J Linn Soc 66:187-203

Rhoads DC (1974) Organism-sediment relationships on the muddy sea floor. Oceanogr Mar Biol Annu Rev 12:263-300

Rosenzweig ML (1995) Species diversity in space and time. Cambridge University Press, Cambridge

Sanders HL (1968) Marine benthic diversity: a comparative study. Am Nat 102:243-282

Schlacher TA, Newell P, Clavier J, Schlacher-Hoenlinger MA, Chevillon C, Britton J (1998) Soft-sediment benthic community structure in a coral reef lagoon - the prominence of spatial heterogeneity and 'spot endemism'. Mar Ecol Prog Ser 174:159-174

Snelgrove PVR (1998) The biodiversity of macrofaunal organisms in marine sediments. Biodiv Conserv 7:1123-1132

Snelgrove PVR (1999) Getting to the bottom of marine biodiversity: sedimentary habitats. Ocean bottoms are the most widespread habitat on earth and support high biodiversity and key ecosystem services. BioScience 49: 129-138

Snelgrove PVR, Butman CA (1994) Animal-sediment relationships revisited: cause versus effect. Oceanogr Mar Biol Annu Rev 32:111-177

Snelgrove PVR, Blackburn TH, Hutchings PA, Alongi DM and 7 others (1997) The importance of marine sediment biodiversity in ecosystem processes. Ambio 26:578-583

Thomas CD, Mallorie HC (1985) Rarity, species richness and conservation: butterflies of the Atlas Mountains in Morocco. Biol Conserv 33:95-117

Thrush SF, Schneider DC, Legendre P, Whitlatch RB and 9 others (1997) Scaling-up from experiments to complex ecological systems: where to next? J Exp Mar Biol Ecol 216:243-254

Ward TJ, Kenchington RA, Faith DP, Margules CR (1998) Marine BioRap guidelines: rapid assessment of marine biological diversity. CSIRO, Perth

Warwick RM, Clarke KR (1991) A comparison of some methods for analysing changes in benthic community structure. J Mar Biol Assoc UK 71:225-244

Warwick RM, Clarke KR (1993) Comparing the severity of disturbance: a meta-analysis of marine macrobenthic community data. Mar Ecol Prog Ser 92:221-231

Warwick RM, Clarke KR (1995) New 'biodiversity' measures reveal a decrease in taxonomic distinctness with increasing stress. Mar Ecol Prog Ser 129:301-305

Whitlatch RB (1981) Animal-sediment relationships in intertidal marine benthic habitats: some determinants of depositfeeding species diversity. J Exp Mar Biol Ecol 53:31-45

Whittaker RH (1960) Vegetation of the Siskiyou Mountains, Oregon and California. Ecol Monogr 30:279-338

Whittaker RH (1972) Evolution and measurement of species diversity. Taxon 21:213-251

Whittaker RH (1975) Communities and ecosystems. Macmillan, New York

Wilson MV, Shmida A (1984) Measuring beta diversity with presence-absence data. J Ecol 72:1055-1064

Wu RSS, Shin PKS (1997) Sediment characteristics and colonization of soft-bottom benthos: a field manipulation experiment. Mar Biol 128:475-487

Submitted: June 15, 2001; Accepted: October 9, 2001

Proofs received from author(s): March 8, 2002 